\title{
Documentation: Complete Cycle of Information Service
}

$\mathrm{D}_{\mathrm{t}}$ OCUMENTATION IS BEST differentiated from normal library service by the extent to which it is concerned with a complete-cycle system of providing information. This cycle involves the identification, recording, organization, storage, recall, conversion into more useful forms, synthesis, and dissemination of the intellectual content of print and other recorded materials.

General library work tends to concentrate in the part of this cycle between recording and recall. Documentation completes the cycle by also dealing with identification, conversion, synthesis, and dissemination.

Documentation is distinguished from general library work in two additional ways. It is more intensive-i.e., subject analysis is carried further, the range of resources accumulated is greater, etc. And documentation has the quality of special, as distinct from general, library service in its relationship to the specialized needs of particular users and uses.

Thus the differentiation of documentation from general library work and from systematic bibliography is primarily a matter of degree. These fields are so closely interrelated that one person may, almost simultaneously, be performing functions in all three. Library functions (such as acquisition, cataloging, and lending, which constitute part, but by

Dr. Shaw is professor, Graduate School of Library Service, Rutgers University. This article is copyrighted, 1957, by the Graduate School of Library Service, Rutgers University. no means all, of library work) are prerequisite to documentation. So, too, systematic bibliography (the listing of literature) is obviously prerequisite to the intensive analysis of intellectual content. If the documentalist or information officer performs the above functions he is, in so doing, acting as a librarian or as a bibliographer. The librarian initiates subject analysis in the cataloging process, but when he moves on to the intensive handling of the ideas contained on every page of every source, he starts to function as a documentalist.

Because of the greater intensity of analysis of intellectual content involved in documentation (and librarians may function as documentalist) greater subject competence is usually required for this field than is required for general librarianship, including systematic bibliography.

Since the conversion of information into new forms is commonly required, and the mass of entries to be handled is normally greater in documentation because of the more intensive subject analysis, and since transmission of information is often necessary, the documentalist must be conversant with more detailed indexing schemes, mechanical storage and handling devices, methods of reproduction, as well as other systems for storage, handling, and retrieval of information than are requisite for general library practice, and he must know how to select and blend these tools into an effective information system.

As indicated by the diagram the core of information that must serve every 


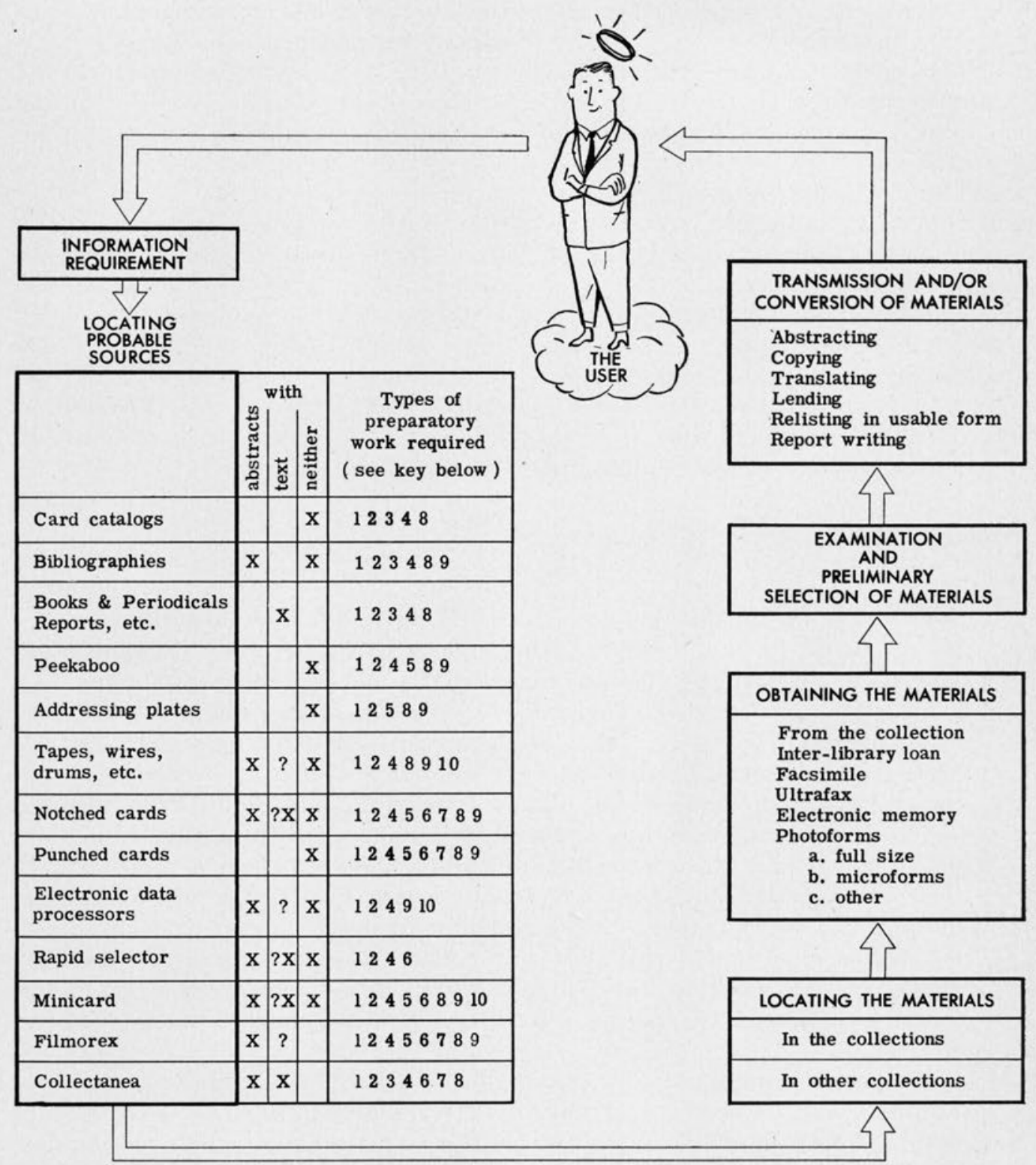

Key to the types of preparatory work that may be required

1. Building the collection

2. Descriptive and subject cataloging and indexing

3. Compilation

4. Reproduction and typing

5. Punching, notching, embossing and/or tabbing
6. Photographing and photo-processing

7. Clipping and mounting

8. Manual filing

9. Machine filing

10. Preparation of programming instructions 
documentalist and information officer, regardless of subject field, includes:

1. The nature and scope of the field.

2. The users served.

3. The collection, organization, and location of probable sources by the various means shown in the diagram on the preceding page.

4. The tools for locating copies of materials to be consulted and for obtaining them either in originals or by various copying devices.

5. The function of evaluation and preliminary selection of the materials to meet a particular need, from the point of view of the particular user, involves a first cut in the intellectual work required of the user. It may include abstracting and other services to help the user to reduce the bulk of material he must consult in order to get everything pertinent to his problem.

6. The tools for conversion of the materials into usable form; including reproducing, translating, report writing, and relisting, as well as the reproduction of reports and lists, etc.

7. The development and operation of balanced full cycle information systems, with all parts fitted into each system so as to provide the information needed, when needed, and in the form in which it is needed by proper blending of the right combination of mechanical and intellectual tools for the particular task or tasks to be performed.

\section{The Faculty of Book Buying}

That the faculty of a university should share the responsibility for buying books for a university library is a generally accepted principle in academic circles. But the realization that book buying is hard intellectual labor comes slowly, if at all, from years of catalog reading. And, unfortunately, the prospect of this hard work added to their teaching load, frightens many faculty members, even those deeply concerned, in the abstract, with strengthening library resources.

The best faculty book buyers have a good idea of what is already in the library, and a broad knowledge of bibliography, ranging far beyond their own special fields of teaching and research. They realize that book catalogs are not bargain counters, and that to delay buying a book today in the hope that it will appear at half the price tomorrow is a delusion. At the same time, they know prices and avoid paying for a bookseller's bad guess. They must know at least as much about books as the sellers.

Such a book buyer was the late Dr. Edward C. A. Lesch, professor of English at the University of Oregon. He recognized that a library is not a series of unrelated segments, but a growing organic entity. He labored as hard over antiquarian catalogs as over his lectures. His recommendations not only supported his own department and other humanistic fields, but the whole field of cultural history, where the sciences, the social sciences, literature, and the arts are seen as varied and mutually illuminating aspects of the life of man. He ordered books unknown to the ignorant, avoided by the timid, and ignored by the narrow specialist. The University of Oregon Library is today immeasurably stronger because of his knowledge and counsel over twenty-nine years. - The Call Number, University of Oregon Library, Fall, 1957. 